\title{
Das ciências às culturas: o problema do patrimônio ${ }^{1}$
}

Stelio Marras ${ }^{2}$

Universidade de São Paulo

\section{Resumo}

Quais os alcances e os limites da noção de patrimônio? Como podemos compreender a noção de patrimônio a partir dos fundamentos da modernidade ocidental? Ou como compreendê-la considerando os pressupostos do mononaturalismo e do multiculturalismo dos modernos? Para isso, esta comunicação focaliza, de modo sintético e teórico, as diferenças entre material e imaterial, bem como entre científico e cultural, a fim de melhor cercar o sentido expresso pela ideia e pela prática da patrimonialização.

Palavras-chave: Cultura. Patrimônio cultural. Pesquisa científica.

\section{From sciences to cultures: the issue of heritage}

What are the scope and limitations of the notion of heritage? How can we understand the notion of heritage from the point of view of the foundations of Western modernity? To put it another way, how can we address it from the standpoint of the assumptions of the moderns' mononaturalism and multiculturalism? In a summarized and theoretical way, this work discusses such questions by focusing on the distinctions between material and immaterial realms - as well as between scientific and cultural realms - in order to better approach the meaning of the ideas and practices of heritage-making

Key words: Culture. Cultural heritage. Scientific research.

Boa tarde. 
Quero logo agradecer o convite de José Tavares Correia de Lira e Fernanda Arêas Peixoto para esse simpósio. Eles me colocaram o desafio de relacionar meu campo de estudos (o Antropologia da Ciência e da Tecnologia, também chamado Science Studies, ou ainda Antropologia da Natureza, Antropologia da Razão, Antropologia dos Modernos) com o tema do simpósio, o patrimônio universitário, com base na experiência que tive no meu Doutorado de etnografar laboratórios de ciência - em especial, laboratórios de biologia e genética na USP. Agradeço pela confiança deles, mesmo diante de minha primeira reação ao convite - que foi de declinar, porque eu francamente não via como pudesse efetivamente contribuir para a discussão desse simpósio. Bem, eles vislumbraram alguma contribuição de minha parte e eu espero não decepcioná-los - ou não muito - com o que afinal eu consegui preparar para apresentar aqui. De todo modo, gostaria de dizer que me sinto muito honrado em participar desta mesa.

É verdade que minha formação em ciências sociais e antropologia poderia levar-me a refletir, como fazem alguns dos meus colegas, sobre patrimônio (e em especial patrimônio cultural) - que de fato é um assunto quente e mostra diversas interfaces com os estudos de antropologia. Mas como eu enveredei por uma Antropologia da Natureza, Antropologia da Ciência e da Tecnologia, acho que estou aqui, nesta mesa, para tentar alguma reflexão sobre como se constitui, ou não se constitui um patrimônio natural a partir do trabalho das chamadas ciências duras, ciências naturais. Em todo caso, eu tenho que assinalar claramente que nunca tive em meu horizonte de pesquisa o tema patrimônio. De maneira que devo marcar, logo de saída, minha exterioridade em relação a esse assunto. Então o melhor que eu mesmo posso esperar aqui é justamente tentar tirar partido dessa minha exterioridade em relação ao tema, tentar converter essa exterioridade em algo produtivo. Evidentemente que não há aí - não pode haver - qualquer garantia de sucesso nessa empreita.

E como nunca refleti sobre o assunto patrimônio, em particular, por isso mesmo achei por bem começar entendendo essa noção de patrimônio (noção originalmente ocidental, moderna) investigando a semântica vernacular do termo a partir de sua etimologia para então entender quais bens podem se candidatar a ser objeto da patrimonialização. Essa é a trilha que eu segui e queria compartilhar com vocês. 
Bem, a semântica de patrimônio imediatamente aponta para uma primeira acepção, essa ligada a bens e herança. E aí diz o dicionário (o Houaiss, que consultei): patrimônio é o "bem ou conjunto de bens naturais ou culturais de importância reconhecida num determinado lugar, região, país ou mesmo para a humanidade, que passa $(\mathrm{m})$ por um processo de tombamento para que seja $(\mathrm{m})$ protegido(s) e preservado(s)".

Penso que de fato essa é a noção majoritária que todos temos mais ou menos em mente quando nos referimos a patrimônio, não é? Portanto, patrimônio dizendo respeito a determinados bens (naturais ou culturais, como expresso no dicionário) que devem ser protegidos e preservados (e preservados para serem legados às gerações futuras, por suposto). E como eu tento praticar uma Antropologia Simétrica (e aí Bruno Latour e Isabelle Stengers são autores que me inspiram a trilhar essa vereda experimental e interdisciplinar das ciências sociais), então me vejo diante da tarefa de entender (e entender com um mesmo tratamento intelectual, donde a pertinência da noção de simetria) a ontogênese tanto dos bens culturais quanto dos naturais, desses bens que se tornarão objeto da patrimonialização. Ou seja, tomarei patrimônio, aqui, como um modo ocidental de classificar determinados bens classificação que reconhece uma espécie de encantamento desses bens especiais: a um só tempo reconhece e dota de encantamento esses bens. Com isso eu já posso ressalvar que, daqui adiante, qualquer coisa que eu disser deve ser ouvida como mera sugestão, meras hipóteses - seja porque não tenho pesquisa sobre o tema (a exterioridade a que me referi...), seja porque o tema (grande e complexo, como vou tentando enunciar e apreender aqui) aparece para mim como, na expressão popular, muita areia para o meu caminhãozinho. Mas com essas tantas ressalvas e precauções, que eu não poderia deixar de logo compartilhar aqui com vocês, pelo menos eu posso agora seguir em frente com as especulações - e especulações muito mais como objeto para nossa discussão aqui e muito menos como assertivas derivadas de alguma pesquisa que de fato não tenho sobre esse tema. E farei isso passo a passo, como alguém que parte do zero para tentar entender um fenômeno que lhe é pouco familiar: Esse caminho que me parece honesto, ainda que diletante; ou diletante, embora honesto. 
É por isso, então, que comecei indo atrás da definição de patrimônio, tal como expressa no dicionário. E é dela que podemos derivar que, naturais ou culturais, estamos falando de bens morais, de coisas morais que devem ser lembradas, praticadas, utilizadas, porque são bens (esses que se tornam patrimônios) animados ou encantados por uma agência capaz de civilizar, educar, dar exemplo a ser seguido, enraizar-se na memória coletiva e na prática social, como ainda evitar certos fenômenos, tal a aniquilação de expressões e diferenças num mundo supostamente globalizado. Seria o caso, por exemplo, do Kwarup, ritual fúnebre de evocação dos mortos praticado pelos índios do Alto Xingu. Sim, decerto não se duvidará da imaterialidade do Kwarup como objeto de patrimonialização. Mas embora o Kwarup apareça aí como um bem imaterial, fato é que muita matéria é mobilizada no ritual - e matéria que aí mesmo mobiliza o conjunto. Lembremos, tão a propósito, que afinal Kwarup significa tronco, sendo o tronco a origem mítica dos homens e por isso objeto central nesse ritual. Quer dizer, não tem Kwarup sem os troncos, sem a sua materialidade.

Faço essa rápida digressão sobre o Kwarup só para dizer que um bem, material ou imaterial, embora esses dois conjuntos vão sempre juntos, como insistirei aqui, pode se tornar objeto de patrimônio (a patrimonialização) porque age coletivamente. Então estamos falando aqui dessa passagem do privado para o público, isto é, do pater, que é a raiz etimológica de patrimônio: o pater como pai da família, dono de seu patrimônio, de seus bens que serão legados para os filhos ou para a linhagem; passagem desse sentido mais privado de pater para o sentido de pater relativo à pátria, aí um bem público que é legado à sociedade, ao coletivo. A raiz latina de pater tem uma semântica que admite, portanto, o privado ou particular, e o público ou coletivo - e também, claro, o gradiente entre esses polos. Ora, o anseio da Unesco (entidade supranacional que nos anos 1970 começa a promover esse conceito de patrimônio e sua prática de patrimonialização), é estender o valor desses bens a um plano universal. Quer dizer, só pode ser objeto de patrimônio aquilo que atinge sentidos coletivos mais amplos - seja então um ritual específico de origem xinguana, seja um trecho da Mata Atlântica - e que imediatamente aparecem como bens a serem preservados, como se esses bens, uma vez dotados da agência moral com o selo do "patrimônio", fossem capazes, como se espera, de seguir distribuindo virtudes sociais e morais mundo afora. 
No caso do ritual do Kwarup e do bioma da Mata Atlântica, o objetivo é preservar, diante de um mundo cujas diferenças estariam sendo sacrificadas, as diferenças particulares, a diversidade - mas diversidade particular que extrapola, e essa a condição para a patrimonialização desses bens, a propriedade particular, já que aí se preserva a diferença, ou se espera preservar, num mundo percebido como massificado, perigosamente igualitário. Percepção essa que me parece muito derivada de uma visão sociológica panorâmica, visão de sobrevoo e muito aderida à autoimagem, cada vez mais frágil ou insustentável, dos modernos sobre si mesmos, isto é, adesão aos preceitos a um só tempo mononaturalistas e multiculturalistas próprios da modernidade. Eu voltarei a isso, mas, de todo modo, essas diferenças, uma vez patrimonializadas, que é praticamente uma musealização viva dos bens, que então são pressionados a se retirar do tempo e de suas transformações sociais e naturais, esses bens passam a compor o acervo universal das diferenças, desde então dispostas à humanidade a título de exemplo, tolerância ou, como se diz, "riqueza cultural e riqueza natural".

É verdade que esse processo gera suas próprias contradições: o Kwarup, por exemplo, tem dono, como um chefe de aldeia que promove o ritual e se responsabiliza por ele. Ainda que aí a noção de dono difira da nossa modernista, algumas questões imediatamente se colocam: como o Kwarup pode gerar uma herança universal e ao mesmo tempo se prender à particularidade às vezes de um chefe indígena, de seu grupo ou clã? Como o ritual pode permanecer idêntico a si mesmo ao longo do tempo, vivendo uma espécie de imunidade ao cosmos e à política? O princípio da proteção ou preservação de alguma coisa (princípio previsto e de fato acalentado na noção de patrimônio) tende a retirar as coisas do fluxo do tempo. Mas o que vive fora do tempo? Certamente os índios sabem dessas contradições internas da noção de patrimônio, mas também sabem das vantagens que essa projeção ocidental da noção de cultura - e com ela a de patrimônio - traz para eles. Ora, esse problema não parece diferente em relação à patrimonialização de paisagens naturais. Quais mudanças podem e não podem acontecer num bioma patrimonializado? Quais mudanças serão consideradas antrópicas e quais não? $\mathrm{Na}$ Amazônia patrimonializada deve-se, desde então, proibir o uso sustentável da flora e da fauna por parte dos índios e das comunidades ribeirinhas? Seja por ação 
antrópica ou não, de que maneira aquilo que é patrimonializado pode se transformar? Eu pergunto: não parece mesmo muito complicado (senão mesmo arbitrário) determinar quanto e como os outros - e aí os outros são tanto humanos como não humanos - devem se modificar? Eu já volto a esses dilemas e contradições da noção de patrimônio para falar dos bens materiais e imateriais da atividade científica.

Por enquanto, eu queria apenas assinalar essa passagem de um a outro sentido de pater (radical de patrimônio) -do sentido mais privado para o outro, mais público -, e que essa passagem parece ser a condição necessária que fornece legitimidade à noção de patrimônio. E é aí que eu incluiria o patrimônio universitário: patrimônio universitário como sinônimo de patrimônio público. Mesmo não se tratando de universidade pública, enunciar algo como patrimônio universitário é já propor a passagem do particular para o público. Ou seja, ao que parece, um bem (natural ou cultural) se candidata à patrimonialização à medida que se desvincula dele a sua propriedade individual inalienável (falo tanto da propriedade material quanto da intelectual, já que as tomo como indistintas, e de onde derivam direitos, royalties, patentes). Ao que parece, então, algo é tão mais objeto de patrimonialização quanto mais alienável seja sua propriedade, quanto mais capaz de se diluir no coletivo. $O$ terreiro baiano de Mãe Menininha do Gantois, tombado pelo Iphan em 2002 e depois agraciado com a Medalha da Diversidade Cultural pela Unesco, em 2010, já não é bem o terreiro da Mãe Menininha ou de sua linhagem, mas sim da comunidade que vive no entorno, também dos visitantes do mundo inteiro; passa, enfim, a ser um item que integra o acervo da diversidade cultural humana.

Talvez já aqui, depois então de cercar ou controlar melhor o conceito de patrimônio com que estou lidando, acho que me sinto um pouco mais habilitado para pensar a extensão e os limites desse conceito em relação aos bens e à produção da atividade científica. Sinto-me um pouco mais seguro para voltar ao campo etnográfico onde trabalhei no meu Doutorado, quando então etnografei atividades de laboratório na USP (laboratórios de biologia, bioquímica, genética) e também em alguns recintos de acesso bem restrito, como os biotérios. E testar, com base nessa minha experiência de campo e nos estudos antropológicos de ciência e tecnologia, a ideia de patrimônio. 
Digo a vocês que, até aqui, o caminho da reflexão me leva a perguntar por que a produção científica nos laboratórios, e os próprios laboratórios e todos os seus equipamentos, não aparecem como objeto de patrimonialização no seu sentido forte. No sentido fraco, ou restrito, claro que todo equipamento da universidade pública é patrimônio público - patrimônio da universidade (por exemplo, da USP) e patrimônio do Estado que a financia (no caso, o Estado de São Paulo). Quem trabalha na universidade pública sabe que não tem equipamento qualquer que não seja patrimonializado. Lá na USP temos justamente o setor de Patrimônio - antes de serem utilizados, os equipamentos devem ser ali cadastrados e receber aquela plaquinha com número de patrimônio. Isso de fato atende a um daqueles sentidos de patrimônio: o que transfere ao bem, à coisa, a propriedade pública, coletiva. E há também o sentido da preservação: o bem deve ser preservado porque ele é público. Sim, público, mas da esfera pública paulista. Já aí, então, vemos que a universalidade do bem universitário também tem a sua restrição. Sim, mas e a produção científica, propriamente dita? Ora, me parece que ocorre aí a mesma coisa. É uma produção feita na universidade pública, com os bens públicos (patrimônio da universidade), mas produção que não figura como patrimônio público no sentido forte. É verdade que podemos dizer, e com todo merecimento, que aquele cientista ou aquela obra científica são patrimônio da universidade, do Estado, do país ou até da humanidade. Mas dizemos isso no sentido figurado - patrimônio no sentido figurado, criado por metáfora. Eu não conheço um cientista ou uma obra científica que tenha ganhado o selo de patrimônio no sentido estrito - que afinal é o sentido com o qual uma Unesco ou um Iphan operam. Galileu, Newton, Darwin ou Freud e suas obras não aparecem em alguma listagem oficial de patrimônio da ciência, do Ocidente ou da humanidade. E por que não? Pergunto: por que a Unesco não prevê que a atividade científica ou os cientistas sejam objeto de patrimonialização? Se me pergunto sobre as razões dessa ausência, logo me lembro, num primeiro momento, do problema da propriedade intelectual, dos royalties e das patentes. Lembro-me que, durante a minha etnografia no Laboratório de Bioquímica e Biofísica do Instituto Butantan eu não podia ter acesso à "rota de obtenção" de um inibidor tumoral (a rota de obtenção é um modo de reproduzir em escala um agente purificado, como a proteína da saliva do carrapato que, no caso daquela pesquisa em curso, se ligava a atividades antitumorais). A pesquisa era 
feita com dinheiro público, com o patrimônio público, mas o acesso a ela por parte de quem, como eu, não estava diretamente envolvido na pesquisa, era impossível. Era segredo de laboratório. E compreensível, já que envolvia direitos de royalties e propriedade intelectual. Acho que isso pode mesmo ser um impedimento à patrimonialização da atividade científica (os cientistas e o que produzem). Ou seja, é preciso que esse conhecimento se torne antigo ou caia em domínio público para que se torne, então, um patrimônio no sentido mais forte. Quer dizer - e esse é o ponto aqui -, é preciso que esse conhecimento científico se torne "cultura" e passe a ganhar o ar encantado da diversidade. E aí eu entendo a razão de a Unesco ou o Iphan insistirem em sempre adicionar à palavra "patrimônio" a palavra "cultural". Quando falam em patrimônio natural eles não estão falando de produtos das ciências naturais, mas sim da natureza como paisagem dada, como a Mata Atlântica, o Cerrado ou a Amazônia, e não de algo construído pelos homens porque a construção é já alguma coisa que tende ao domínio da cultura e da diversidade do engenho humano. Quer dizer, a diversidade natural não é obra da ciência natural. De fato, o signo clássico ou moderno das ciências naturais é o da unidade (a verdade no singular, a razão última das coisas) e não a diversidade.

É verdade que em 2010 o Comitê de Patrimônio Mundial da Unesco endossou, pela primeira vez, um estudo sobre o patrimônio científico. Mas era um estudo sobre locais de patrimônio da astronomia e arqueoastronomia. Foi o caso, por exemplo, daquelas antiquíssimas tumbas em Portugal, monumentos de pedra que teriam servido para o conhecimento astronômico dos antigos. Mas aí o que se quer preservar é muito mais o sítio arqueológico, que estudado pela ciência feita hoje poderá revelar menos uma expressão da natureza astronômica do cosmos (que é afinal a promessa das ciências naturais) e mais o conhecimento dos antigos, conhecimento esse já revestido do signo do diverso, um conhecimento cultural da natureza, e não um conhecimento da natureza, como quer o nosso pensamento oficial científico da modernidade. Para esse pensamento científico oficial da modernidade, qual verdade astronômica antiga pode superar o que hoje se obtém com os mais refinados instrumentos tecnológicos? O que resiste à ótica avançada e aos cálculos de supercomputadores? Diante destes, aquela verdade antiga se torna apenas uma verdade, vamos dizer, "cultural". Uma verdade relativa, já um etnoconhecimento (possível objeto de preservação patrimonial) e não mais uma verdade 
natural, uma verdade com $\mathrm{V}$ maiúsculo, um conhecimento que se desprende do chamado contexto cultural, um conhecimento que não se admite étnico (porque étnicos, para os modernos, são sempre os outros). Ou seja, estamos de novo diante da diversidade do conhecimento. É quando, me parece, o conhecimento natural passa a ser recoberto, por efeito da história e do distanciamento, ou por efeito, sobretudo, do multiculturalismo pressuposto pelo Ocidente moderno, disso que chamam de "valor cultural". E como valor ou cultura (e não como razão ou natureza) é que as coisas podem aparecer como objeto de patrimonialização, objeto de preservação, porque valores e culturas seriam sempre variáveis e diversos. E como variáveis e diversos (no modo moderno ou ocidental de entender) é que podem ser esquecidos ou menosprezados - simétrica razão porque podem, ou devem, se candidatar a patrimônio a ser preservado na memória coletiva e legado às gerações futuras. Nós, modernos, tomamos a cultura como algo de verdade relativa, contextual, que se prende a uma determinada configuração étnica. Já a natureza expressa pelas ciências naturais, a natureza descoberta e revelada, essa não aparece como étnica ou cultural, mas se reveste da verdade absoluta - ou até prova em contrário. E por que preservar a verdade natural revelada pela ciência se ela já seria transparente por si mesma, autoevidente, tão eficaz e sempre incorporada às coisas e ao nosso comportamento cotidiano? Essa me parece ser a razão porque, na modernidade, o objeto da patrimonialização deva sempre ser do domínio da cultura. A Unesco não está chancelando o conhecimento natural (e muito menos sobrenatural) do Kwarup ou do terreiro de Mãe Menininha do Gantois. O que há ali de natural ou sobrenatural aparece como englobado pela cultura - cultura indígena, negra, mestiça. Eis o que quis apontar nesta comunicação. Obrigado.

\section{Notas}

1 Texto de conferência da mesa Ciência e Patrimônio apresentado no simpósio Patrimônio Universitário, promovido pelo Centro de Preservação Cultura da USP, na Casa de Dona Yayá, pelo Departamento de Antropologia da USP e pela Faculdade de Medicina da USP em março de 2012. Entendi por bem manter aqui o formato aproximadamente informal da exposição original, assim visando maior alcance da comunicação junto aos leitores ao preservar certa fluidez que uma conferência permite. 
2 Professor de antropologia do Instituto de Estudos Brasileiros (IEB) da Universidade de São Paulo (USP). Pesquisador do Centro de Estudos Ameríndios (CESTA) da USP. E-mail: smarras@usp.br 